\title{
Characterisation of polycyclic aromatic hydrocarbons in flue gas and residues of a full scale fluidized bed combustor combusting non-hazardous industrial waste
}

\author{
J. Van Caneghem ${ }^{a, b,{ }^{*}}$, C. Vandecasteele ${ }^{a}$
}

a Department of Chemical Engineering, University of Leuven, Willem de Croylaan 46, 3001 Leuven, Belgium

b Group T Leuven Engineering College, Association of the University of Leuven, Andreas Vesaliusstraat 13, B-3000 Leuven, Belgium, jo.vancaneghem@kuleuven.be

${ }^{*}$ corresponding author

\section{Abstract}

This paper studies the fate of PAHs in full scale incinerators by analysing the concentration of the 16 EPA-PAHs in both the input waste and all the outputs of a full scale Fluidized Bed Combustor (FBC). Of the analysed waste inputs i.e. Waste Water Treatment (WWT) sludge, Refuse Derived Fuel (RDF) and Automotive Shredder Residue (ASR), RDF and ASR were the main PAH sources, with phenanthrene, fluoranthene and pyrene being the most important PAH. In the flue gas sampled at the stack, naphtalene was the only predominant PAH, indicating that the PAH in FBC's combustion gas were newly formed and did not remain from the input waste. Of the other outputs, the boiler and fly ash contained no detectable levels of $\mathrm{PAH}$, whereas the flue gas cleaning residue contained only low concentrations of naphthalene, probably adsorbed from the flue gas. The PAH fingerprint of the bottom ash corresponded rather well to the PAH fingerprint of the RDF and ASR, indicating that the PAHs in this output, in contrast to the other outputs, were mainly remainders from the PAHs in the waste inputs. A PAH mass balance showed that the total PAH input/output ratio of the FBC ranged from about 100 to about 2,600 depending on the waste input composition and the obtained combustion conditions. In all cases, the FBC was clearly a net PAH sink.

Keywords

Polycyclic aromatic hydrocarbons, PAH, waste, incineration, FBC 
Polycyclic aromatic hydrocarbons (PAH) are a group of hundreds of chemically related environmentally persistent organic compounds with various structures and varied toxicity (Agency of Toxic Substances and Disease Registry, 1995). PAHs are typical products of incomplete combustion (Vehlow et al., 2006). Some PAHs, including benzo(a)pyrene and chrysene, are classified as probable or possible human carcinogen by the International Agency for Research on Cancer (IARC). In comparison with polychlorinated dibenzo-dioxins and furans (PCDD/Fs), which are other typical products of incomplete combustion, the formation mechanisms and especially the emission of $\mathrm{PAH}$ from waste combustors received little attention so far.

Although in modern waste combustors air supply, mixing of air and waste and gas residence time are carefully controlled, the presence of low concentrations of PAHs in the flue gas and solid residues cannot be avoided. Only few studies on PAH formation and destruction in waste combustors have been reported. Thomas and Wornat (2008) studied the formation and fate of PAHs from complex solid fuels as a function of temperature $\left(500-1000^{\circ} \mathrm{C}\right)$ and oxygen supply (zero to near stoichiometric). They distinguish two competing effects of oxygen. The first is the "radical enhancement effect", involving increased formation of free radicals with increasing oxygen rate (OR) (OR equals 1 if a stoichiometric amount of oxygen is supplied), leading to a higher yield of pyrolytic breakdown products, which recombine to form PAHs. The second effect is the "oxidative destruction effect", involving an increased oxidative breakdown of earlier formed pyrolysis products, including PAHs, with increasing OR. The relative importance of both effects is highly dependent on the combustion temperature: at temperatures below $800^{\circ} \mathrm{C}$ and $\mathrm{OR}<1$, the radical enhancement effect is more important and an increase in oxygen supply increases $\mathrm{PAH}$ formation. At temperatures above $800^{\circ} \mathrm{C}$ and $\mathrm{OR}<1$, oxidative destruction becomes more important and an increase in oxygen supply will decrease the PAH formation rate (Thomas and Wornat, 2008). Herrera et al. (2002) studied the formation of PAHs during thermal degradation of polyurethane elastomers. They burned two different types of polyurethane and analysed the combustion gas. Of the 16 EPA PAHs measured, naphthalene occurred in the highest concentration. Herrera et al. (2002) conclude that PAHs are formed by precursor recombination: in a first stage benzene is formed that further "grows" to higher molecular weight PAHs. Indeed, the concentration of naphthalene (2 rings) was higher than the 
concentration of phenanthrene (3 rings) whose concentration again was higher than that of pyrene (4 rings). The PAH concentrations measured in the combustion gas were very similar for the different polyurethanes, so PAH formation did not seem to depend on the molecular structure of these elastomers. Kwon and Castaldi (2012) studied the thermal degradation of tires in air atmosphere and also in these experiments, the concentration of naphthalene was the highest of all PAH analysed in the combustion gas.

In waste combustors, the first stage of the combustion process takes place in a furnace where only substoichimometric amounts of oxygen are present. The waste is volatilised and pyrolysed and the pyrolysis products recombine to form $\mathrm{PAH}$ in the raw combustion gas. In the second stage, that takes place in a post combustion chamber, secondary air is supplied to the raw combustion gas and the volatilised products and earlier formed PAHs are destroyed by oxidation, leading to higher temperatures than in the primary combustion stage (Watanabe et Noma., 2009). The fact that PAHs found in raw combustion gas are newly formed by pyrosynthesis and not directly evaporated from the waste was demonstrated by Atal et al. (1997), who added deuterium spiked PAHs to the waste feed of a lab scale furnace. None of these deuterium spiked PAHs were detected in the raw flue gas, so they were destroyed during combustion and the PAHs in the flue gas were newly formed. Watanabe and Noma (2009) determined the concentration of PAHs, expressed in mg (t waste input) $)^{-1}$, in the raw combustion gas of a pilot scale rotary kiln incinerator fed with municipal solid waste (MSW) and showed that the concentration of PAHs was 1 (combustion temperature $890^{\circ} \mathrm{C}$ ) to 3 (combustion temperature $690^{\circ} \mathrm{C}$ ) orders of magnitude higher than in the waste input. They come to similar conclusions as Atal et al. (1997) and Thomas and Wornat (2008) i.e. that PAHs were formed in the primary combustion zone and at higher rates at $690^{\circ} \mathrm{C}$ than at $890^{\circ} \mathrm{C}$. Watanabe and Noma (2009) also showed that the PAH formed in the kiln were largely destroyed in the secondary combustion chamber: the total PAH concentration of the combustion gas leaving the secondary combustion chamber was 3-4 orders of magnitude lower than the PAH concentration in the raw combustion gas entering the chamber, corresponding to a destruction efficiency $>99 \%$. Filtration over an active carbon filter and wet flue gas treatment had no significant influence on the total amount of PAHs in the combustion gas. 
Besides the combustion air, PAHs are also present in solid residues of waste incinerators. Wheatley and Sadhra (2004) studied PAH in the bottom and fly ash from a modern full scale clinical waste incinerator. They suggest that the PAH in the bottom ash may be a combination of those present in the waste (which were not completely destroyed during combustion) and those formed in the primary combustion process. In the experiments of Watanabe and Noma (2009), the PAH concentration in the bottom ash of the pilot scale rotary kiln, expressed in $\mathrm{mg}$ (t waste input) $)^{-1}$, was 1.5 to $15 \%$ of the PAH concentration in the input MSW. The highest concentrations were detected for the lowest kiln temperature applied $\left(690^{\circ} \mathrm{C}\right)$, which agrees with the results of Thomas and Wornat (2008). The total PAH concentration in the fly ash collected in a bag filter placed downstream of the boiler was much lower than the concentration in the bottom ash and corresponded to about $1 \%$ of the MSW input concentration, which was $3000 \mu \mathrm{g} \cdot \mathrm{kg}^{-1}$.

The findings on PAH formation in waste combustion processes discussed here (Thomas and Wornat (2008); Herrera et al. (2002); Watanabe and Noma (2009); Atal et al., 1997), were obtained in lab scale or pilot scale installations in which the parameters influencing $\mathrm{PAH}$ formation (e.g. temperature and oxygen rate) can be controlled within narrow margins. It is however not yet clear what the implications of these findings are for full scale installations. Only a few papers study the fate of PAHs in full scale waste incinerators and often these studies only report PAH concentrations in the incinerator outputs i.e. flue gas and/or ashes (Johansson and Van Bavel, 2003; Wheatley and Sadhra, 2004). It should also be kept in mind that in full scale waste incinerators, in addition to the outputs i.e. ashes and flue gas, also the waste input contains PAHs. Therefore this study reports, to our knowledge for the first time, the concentration of the 16 EPA-PAHs in both the input waste and all the outputs i.e. flue gas, boiler and fly ash, flue gas cleaning residues and bottom ash of a full scale FBC combusting non-hazardous (industrial) waste. Furthermore, the concentrations of the individual PAHs or so called "PAH Fingerprint" of the waste inputs and outputs are compared in order to find out to which extend $\mathrm{PAH}$ in the outputs remain from the input waste or are newly formed. Finally, a PAH mass balance is drawn up to determine the major $\mathrm{PAH}$ input and output streams and to establish whether the FBC is an overall PAH sink or source.

2. Materials and methods

2.1 FBC 
The FBC under study was described in detail in previous work of the authors (Van Caneghem et al., 2010a; Van Caneghem et al., 2012). In the FBC, high calorific RDF from mechanical biological treatment of MSW and comparable industrial waste afford the heat necessary for drying and incinerating low calorific waste water treatment (WWT) sludge, and for steam and electricity generation. In 2011, the installation, which is situated in Flanders, Belgium, incinerated $560 \times 10^{3} \mathrm{t}$ of mixed waste. The FBC is of the ROWITEC internal rotating fluid bed type in which a sand mass is fluidized by hot air. The RDF is together with the WWT sludge introduced and combusted in the fluidized sand bed. In the freeboard, which is the free space above the fluidized bad that acts as post combustion zone, a gas temperature of at least $850^{\circ} \mathrm{C}$, a residence time of at least $2 \mathrm{~s}$ and an oxygen excess of at least $6 \%$ are maintained to ensure proper burn out. In a vertical boiler, energy is recovered from the hot combustion gases. The produced superheated steam ( $\left.40 \mathrm{bar}, 400^{\circ} \mathrm{C}\right)$ is sent to a turbine (capacity of $34 \mathrm{MW}$ ) for electricity production. The flue gas is dedusted in an electrostatic precipitator and flows through a flue gas cleaning installation consisting of a semi-dry reactor, a baghouse filter and a caustic soda scrubber. A mixture of clay and activated carbon particles $\left(\right.$ Dioxorb $^{\circledR}$ ) is injected in the semi-dry reactor to adsorb PCDD/Fs. At the bottom of the FBC, the sand and ashes are removed after which the sand is sieved of and sent back into the incinerator. The boiler and fly ash and the flue gas cleaning residues are solidified and stabilised and subsequently stored on a hazardous waste landfill. The bottom ash goes to a specialized facility for recycling. Figure 1 gives a schematic overview of the installation, indicating the average temperatures at the different stages of the combustion and flue gas cleaning process. 


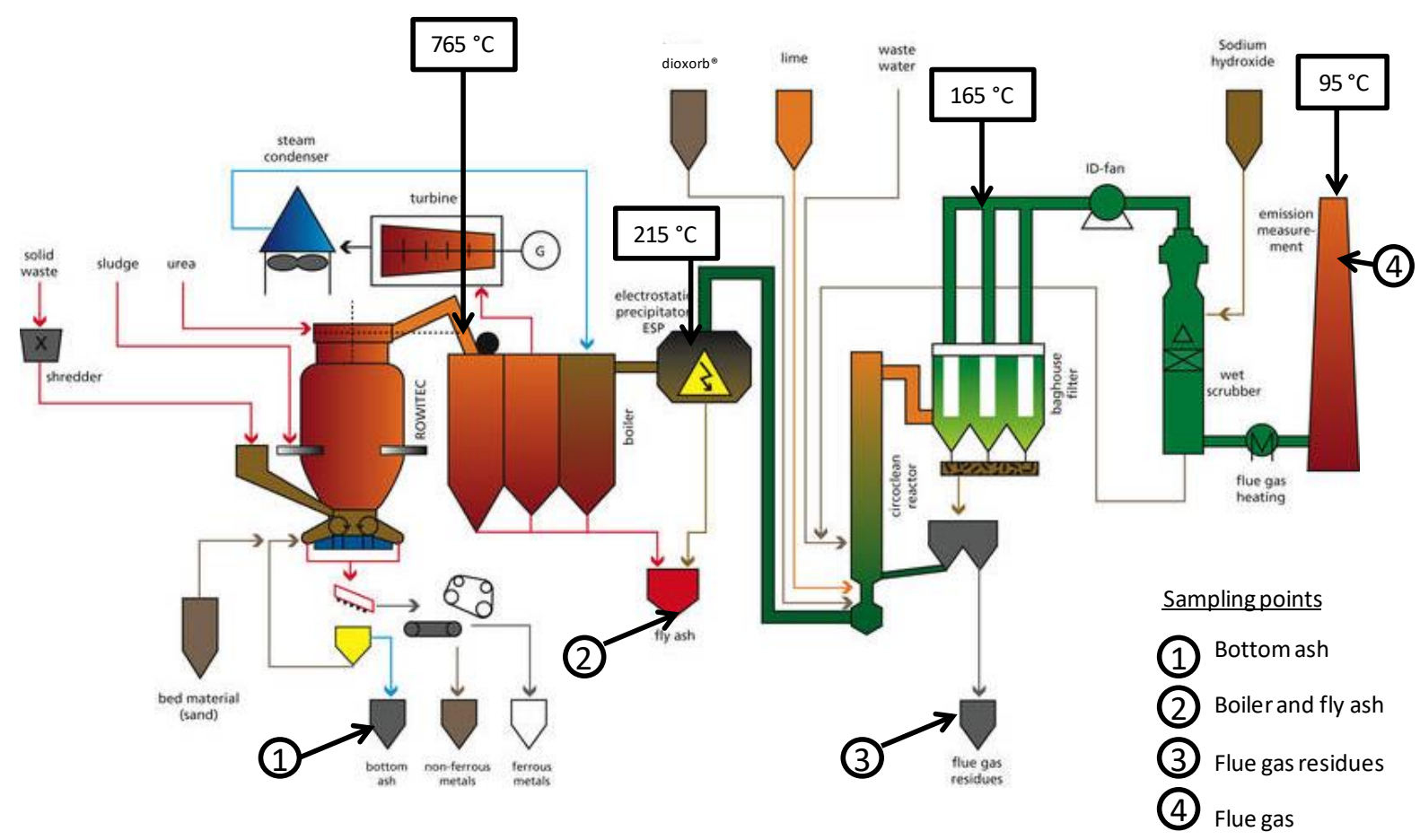

Figure 1: Schematic overview of the FBC with indication of sampling points and temperatures at different stages of the installation

\subsection{Waste types}

The two main waste types combusted in the FBC are RDF and WWT sludge. However, occasionally also non hazardous industrial wastes are combusted. One of these wastes is automotive shredder residue (ASR) and is considered in this study.

The RDF combusted in the FBC is one of the remaining fractions of mechanical biological treatment (MBT) of Flemish MSW. The MBT-process of interest here, consists of biological drying (the shredded waste is put in an insulated bunker during one week and is dried by the heat resulting from largely aerobic biological activity) which reduces the mass by $25-30 \%$, followed by mechanical, magnetic, eddy-current and hand separation. The resulting output streams are inert materials (sand, china, glass) accounting for 10 to $15 \%$ of the initial waste mass, metals (5\% of the initial waste mass) and RDF containing mainly plastics, paper and dried organic material ( $55 \%$ of the initial waste mass). The RDF "as received (AR)" has an average lower heating value (LHV) of $12 \mathrm{MJ} / \mathrm{kg}$. 
The second waste stream combusted in the FBC is WWT sludge. The sludge incinerated in the FBC mainly comes from municipal and industrial biological wastewater treatment plants. It is a mixture of dewatered and digested sludge with an average dry matter content of $24 \%$. The average LHV (AR) of the sludge incinerated in the $F B C$ is $2 \mathrm{MJ} / \mathrm{kg}$.

The combusted ASR consists of the "heavy" ASR fraction, which is the remaining fraction after separation of ferrous, non-ferrous and plastic materials and does not include the fluff collected by the air suction installation at the main shredder. It contains a mixture of combustible (mainly PU-foam, plastic fibres and foil) and inert materials (sand, small stones, iron and rust particles). The ASR particle size was reduced in order to make it suitable for injection in the FBC. The average ash content of the incinerated ASR is $53 \%$, the average LHV (AR) is $19 \mathrm{MJ} / \mathrm{kg}$.

In order to maintain a stable temperature in the steam boiler, practice has shown that the input waste mix should have a LHV (AR) of about $8.5 \mathrm{MJ} / \mathrm{kg}$. This is obtained for a waste mix consisting of $70 \%$ (mass\%) RDF and 30\% WWT sludge, further referred to as "the usual waste mix", as most of the time these are the only two waste types incinerated. The term "mix" is chosen here for reasons of conciseness since the wastes are not actually mixed before combustion but introduced separately (Figure 1). In case also ASR is combusted, the desired LHV was obtained for a waste mix consisting of $25 \%$ RDF, $25 \%$ ASR and $50 \%$ of WWT sludge, further referred to as the "ASR waste mix". The percentage ASR was limited to $25 \%$ as practice has shown that higher proportions of ASR can destabilise the fluidised bed.

\subsection{Sampling and analytical techniques}

The first sampling campaign was conducted when the usual waste mix was combusted. During this campaign, only the outputs of the FBC were sampled as the inputs (RDF and the WWT sludge) were sampled in the second campaign. The flue gas was sampled during 14 days and for each solid output, one pooled sample was made by mixing daily samples during the 14 day period.

The second sampling campaign was conducted when, during one week, a mix of RDF, ASR and WWT sludge was combusted. The different waste types combusted in the FBC were each mixed and homogenized at the production location before they were transported to the plant. During two nonconsecutive days, a representative 5-liter sample was taken from each truck load of each of the waste 
streams. On each day, about 20, 25 and 50 truckloads of ASR, RDF and WWT sludge were delivered, respectively. At the end of the second and fourth day of that week, the samples of each waste stream were thoroughly mixed and shredded. Part of this shredded mixture was then analyzed. In this way, the measured PAH concentrations can be considered average concentrations for the wastes delivered that day. The FBC outputs were sampled in the same way as the waste inputs: on the second and the fourth day, of each output five 5 -liter samples were taken and pooled as described for the waste inputs. The flue gas was sampled continuously during that week and pooled samples of the different waste types and the FBC outputs were made, on the second and fourth day of that week, respectively. All output samples were taken during normal, steady state operation of the FBC during which no major changes in air factors or waste feeding rates possibly influencing PAH formation took place. Furthermore, the emission of all regulated pollutants e.g. $\mathrm{CO}, \mathrm{NO}_{x}, \mathrm{SO}_{x}$, heavy metals, PCDD/Fs was monitored and their concentrations stayed well beyond the legal emission limit values indicating stable and complete combustion.

The sampling points of the different outputs considered in this study are indicated on Figure 1.Of the FBC's solid residues, pooled samples were obtained by mixing samples taken at different times during one day. The PAH concentrations in the sampled waste types and FBC outputs were analysed by a certified laboratory that has to participate regularly in government-organised inter-comparisons in order to demonstrate quality.

In the sampled waste types and solid residues, the 16 EPA PAHs were analysed by HPLC-UV fluorescence after soxhlet extraction and clean-up according to the CMA/3/B method (VITO, 2006). The detection limit was $10 \mu \mathrm{g} / \mathrm{kg}$. The average measurement uncertainties varied from $20 \%$ for anthracene and benzo(b)fluoranthene to $40 \%$ for the other measured PAHs.

Flue gas was sampled continuously using sampling equipment of the AMESA (Adsorption Method for Sampling) type located on a measuring platform at the stack, according to the EN 1948-1 standard as described in Van Caneghem et al. (2010b). The sampling train consisted of a glass fibre PFTE coated filter, a glass cooling unit with condensate collection and a cartridge filled with XAD-2 adsorption resin. After extraction of the the particulate matter retained on the filter, the collected condensate and the adsorbing material, PAHs were cleaned-up by means of a multi-layer alumina and silica gel 
column and analysed by GC-MS according to the LUC/VI/001 method (VITO, 2013). The detection limit was $0.001 \mu \mathrm{g} / \mathrm{Nm}^{3}$. The average measurement uncertainty was $20 \%$.

\section{Results and discussion}

\subsection{PAH in input waste types}

Of the three waste types analysed, WWT sludge had the lowest total PAH concentration i.e. 340 and $740 \mu \mathrm{g} \mathrm{kgDm}^{-1}$ in the two pooled samples, respectively. Naphtalene and phenanthrene were the only 2 of the 16 EPA PAHs found in concentrations above the detection limit $(10 \mu \mathrm{g} / \mathrm{kg})$. The pooled RDF samples contained 5,319 and 8,435 $\mu \mathrm{g} \mathrm{kgDm}^{-1}$, respectively, whereas the pooled ASR samples had the highest PAH concentrations i.e. 36,910 and $142,600 \mu \mathrm{g} \mathrm{kgM}^{-1}$. The concentrations in the RDF are higher than reported by Ruokojärvi et al. (1995) for household waste in a Finish landfill $(2,000 \mu \mathrm{g}$ $\left.\mathrm{kg}_{\mathrm{DM}}^{-1}\right)$, reported by Brändli et al. (2007) for green and organic kitchen waste $\left(410-3,320 \mu \mathrm{gggm}^{-1}\right)$ or reported by Watanabe and Noma (2009) $\left(3,000 \mu \mathrm{ggDm}^{-1}\right)$ for MSW.

The average concentrations of the individual PAHs in the pooled samples, relative to the total PAH concentration in the RDF and ASR (PAH fingerprints) are shown in Figure 2.



Figure 2: Concentrations of the individual EPA PAHs in the RDF and ASR (\% of the total concentration of the 16 EPA PAHs) 
Figure 2 shows that ASR contains more 5 to 6 ring PAH (PAH from benzo(b)fluoranthene to ideno(1,2,3-c,d)pyrene on X-axis in Figure 2) than RDF, but in both waste types phenanthrene, fluoranthene and pyrene are the most important PAH. The relative importance of naphthalene is much lower in RDF and in ASR, where its concentration is close to or below the detection limit, than in WWT sludge, where naphthalene accounts for $94 \%$ of the total PAH output. This indicates that RDF/ASR and WWT sludge are contaminated by different PAH sources.

\subsection{PAH in the FBC outputs}

The total PAH concentration in the flue gas sampled in the stack during combustion of the usual waste mix (RDF and WWT) and the ASR waste mix (RDF, ASR and WWT sludge) was 7.46 and 0.79 $\mu \mathrm{g} / \mathrm{Nm}^{3}$, respectively. The lower value in case of ASR co-combustion was unexpected; apparently a better burnout was achieved in this case. As can be seen from Figure 3, naphtalene accounted for $98 \%$ of the total PAH concentration in both cases. Acenaphtylene, fluorene and phenanthrene were the only other PAH present in concentrations (just) above the detection limit. The correspondence between the PAH fingerprint of the flue gas of the FBC and the WWT sludge (94\% naphthalene, $6 \%$ phenanthrene) indicates that emissions from (waste) combustion processes are probably an important source of PAH contamination of the sludge. Indeed, PAHs adsorbed to particulate matter emitted by combustion processes can be washed out with rain and, as in Flanders no separate sewer system for domestic wastewater and rain water exists, eventually end up in the WWT sludge. 


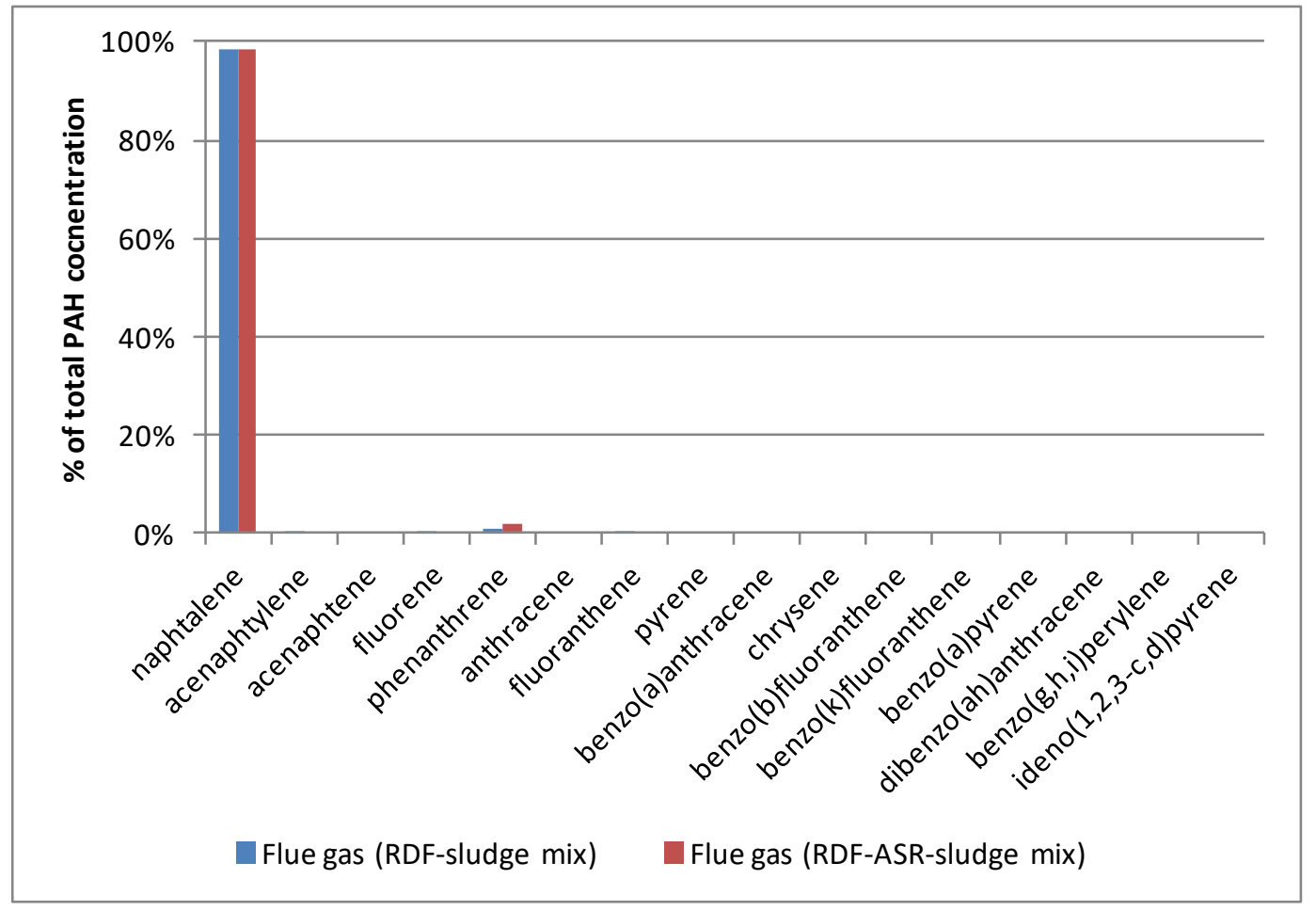

Figure 3: Concentrations of the individual EPA PAHs in the FBC's flue gas sampled during incineration of the usual and ASR waste mix ( $\%$ of the total concentration of the 16 EPA PAHs)

In the boiler and fly ash (collected together in the installation as indicated in Figure 1), none of the measured PAHs were present in concentrations above the detection limit $(10 \mu \mathrm{g} / \mathrm{kg})$ during usual waste mix combustion, nor during co-combustion of ASR. This indicates that the ash entrained with the combustion gas and collected in the boiler and ESP (Figure 1) does not contain PAHs remaining from the waste nor PAHs adsorbed from the gas phase. The absence of $\mathrm{PAH}$ in incinerator fly ash was also observed by Wheatley and Sadhra (2004) in a full scale medical waste incinerator. Vehlow et al. (2006) reported total PAH concentrations in boiler and fly ash of MSW incinerators ranging from 0.4 to $17,795 \mu \mathrm{ggDM}^{-1}$, but most measurements dated from the 1980ies and 1990ies and are therefore no longer representative for modern well managed waste incinerators equipped with Best Available Technology (BAT) and complying with the European Directive on Industrial Emissions (Directive 2010/75/EU).

The flue gas cleaning residue collected in the baghouse filter (Figure 1) contained only naphthalene in concentrations above the detection limit. The pooled sample collected during normal waste mix incineration contained $36 \mu \mathrm{g} \mathrm{kgM}^{-1}$ naphtalene. One of the pooled samples collected during ASR co- 
combustion contained $12 \mu \mathrm{g} \mathrm{kg} \mathrm{DM}^{-1}$, in the other pooled sample, the concentration of all $16 \mathrm{PAH}$ was below the detection limit. The fact that the flue gas cleaning residue contains slightly higher naphtalene concentrations than boiler and fly ash which are collected further upstream in the installation indicates that the residue particles in the baghouse filter, in this case containing activated carbon particles primarily injected for PCDD/F removal, adsorb naphthalene from the flue gas. This indication is sustained by the results of Watanabe and Noma (2009), where the total PAH concentration in the flue gas of a pilot scale incinerator decreased by $15-50 \%$ when passing through a bag filter.

A comparison the PAH fingerprints of the flue gas, boiler and fly ash and flue gas cleaning residue, dominated by naphthalene, with the fingerprints of the input wastes discussed in Section 3.1 and Figure 2, dominated by phenanthrene, fluoranthene and pyrene shows that the PAHs in both waste mixes are destroyed during combustion. This confirms the conclusion of Atal et al. (1997) i.e. that PAHs in the waste are destroyed and PAHs found in the flue gas are newly formed from pyrolysis breakdown products.

The total PAH concentration in the pooled bottom ash sample collected during combustion of the normal RDF sludge mix was $269 \mu \mathrm{g} \mathrm{kg} \mathrm{DM}^{-1}$. The two pooled bottom ash samples collected during cocombustion of ASR contained 10 and $74 \mu \mathrm{g} \mathrm{kgDM}^{-1} \mathrm{PAH}$, respectively. Johansson and van Bavel (2003) reported concentrations of the 16 EPA-PAH in MSW combustor bottom ash ranging from 479 to $3589 \mu \mathrm{g} / \mathrm{kg}$. Wheatley and Sadhra (2004) reported a total PAH concentration of about $450 \mu \mathrm{g} \mathrm{kg}$ DM

1 in bottom ash of a pulsed hearth clinical waste incinerator. Vehlow et al. (2006) reported total PAH concentrations in bottom ash of MSW combustors ranging from $114-545 \mu \mathrm{ggDm}^{-1}$ (only samples taken in 2000 and later). These concentrations are in line with the total PAH concentration of 570-680 $\mu \mathrm{kgDM}^{-1}$ in bottom ash of a grate furnace incinerating MSW earlier reported by the authors (Van Caneghem et al., 2010b). The fact that the PAH concentration in the bottom ash of the FBC under study here is lower than in the bottom ash of a grate furnace combusting comparable waste, indicates a more complete waste burnout in the FBC.

The concentration of the individual PAHs relative to the total PAH concentration in the bottom ash collected during sludge-RDF combustion and sludge-RDF- ASR combustion (average concentration of the two pooled samples) is shown by the left bars in Figures 4 and 5, respectively. 


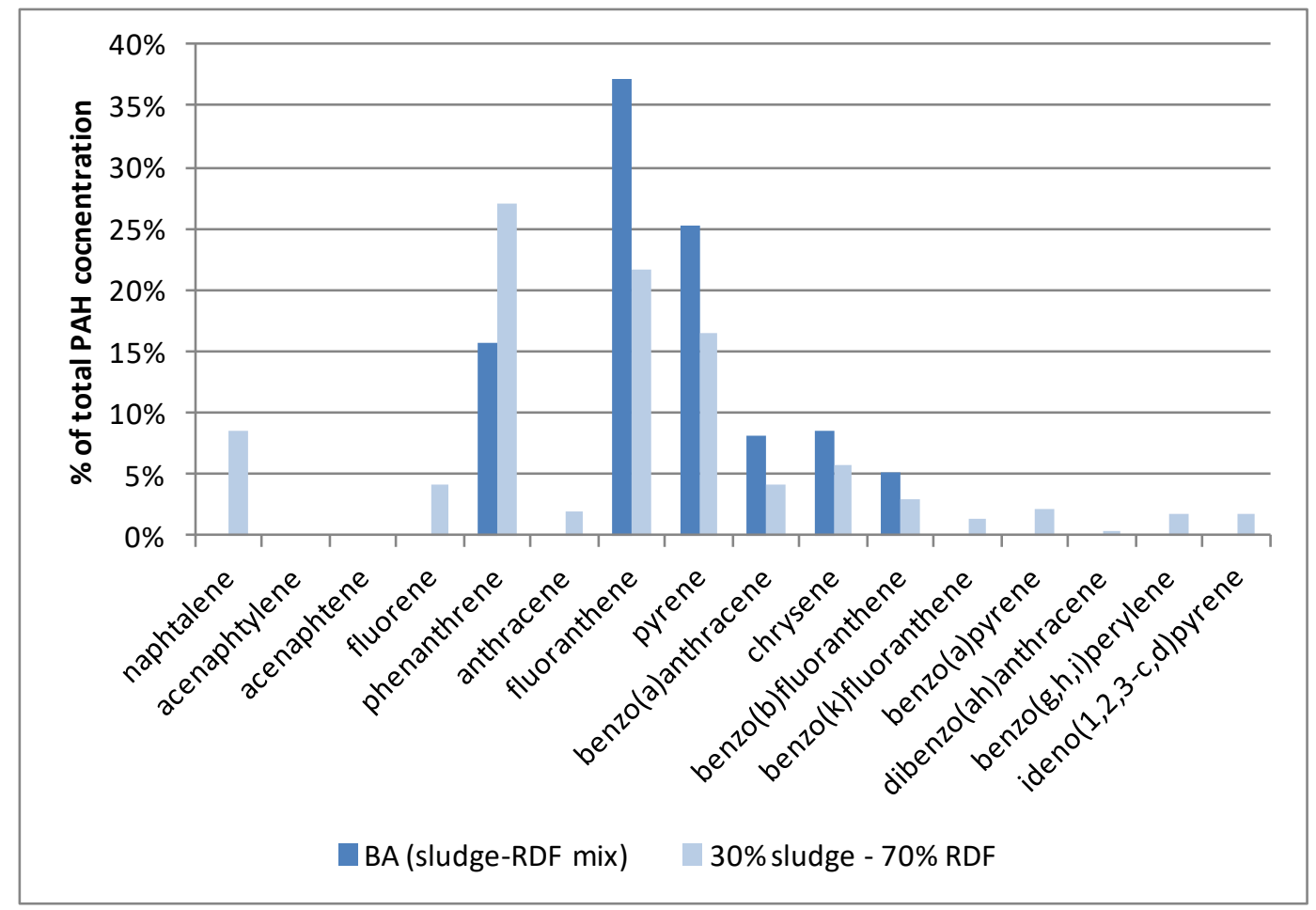

Figure 4: Concentrations of the individual EPA PAHs in the bottom ash of the FBC (sampled during incineration of the usual waste mix) and in the usual waste mix (\% of the total concentration of the 16 EPA PAHs)

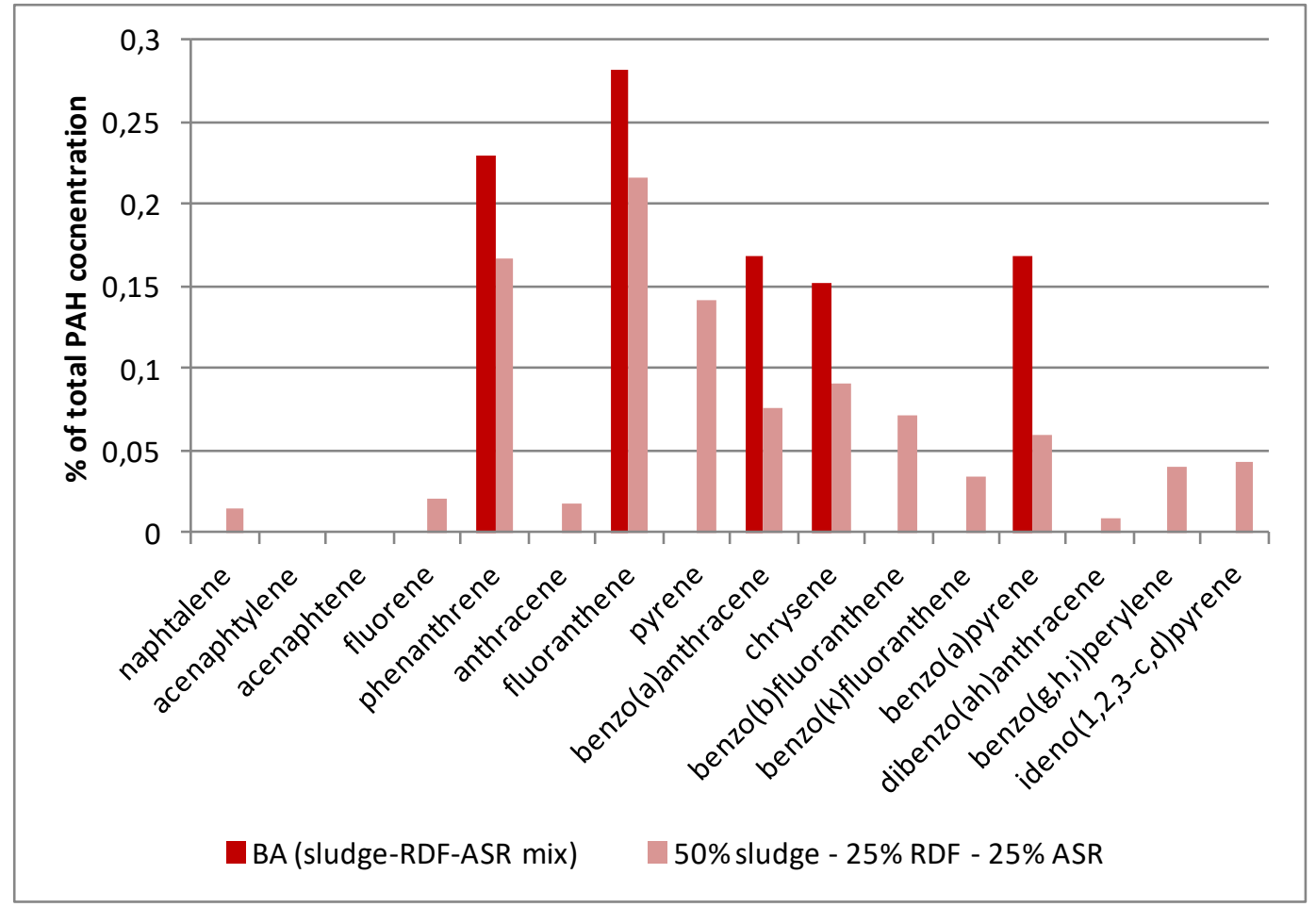

Figure 5: Concentrations of the individual EPA PAHs in the bottom ash of the FBC (sampled during co-incineration of the ASR waste mix) and in the ASR waste mix (\% of the total concentration of the 16 EPA PAHs) 
In the bottom ash collected during combustion of the usual waste mix, phenanthrene, fluoranthene and pyrene have the highest relative concentrations. In the bottom ash analysed by Johansson and van Bavel (2003) the most important PAHs were naphthalene, phenanthrene and to a lesser extent fluoranthene and pyrene, corresponding rather well to the PAH fingerprint in Figure 4. In the usual waste mix, RDF is the most important source of PAH (see Section 3.1). To investigate if the PAHs in the bottom ash remain from the waste input or are newly formed, Figure 4 also gives the concentrations of the individual PAHs relative to the total PAH concentration in the $30 \%$ WWT sludge - 70\% RDF waste mix (calculated from the concentrations given in Section 3.1 and Figure 2).

Comparing the $\mathrm{PAH}$ fingerprints given in Figure 4 shows that phenanthrene, fluoranthene and pyrene are the most important PAH in both the waste mix and the bottom ash, indicating that the PAH in the bottom ash are most likely remainders from the PAH in the waste. Figure 5 also shows a good correspondence between the relative concentration of the PAH in the input waste mix and in the bottom ash in case of ASR co-combustion, although less pronounced than in Figure 4. The concentration of pyrene for instance, which is one of the PAH present in the highest concentrations in the waste mix, was below the detection limit in the bottom ash.

Figures 3 and 4 also show that the FBC under study assures complete combustion, regardless of the input waste mix composition i.e. only WWT sludge and RDF or of WWT sludge, RDF and ASR.

\subsection{Mass balance, PAH input/output ratio}

Table 1: Total mass of PAHs in the inputs and outputs of the FBC (t year-1), PAH input/output ratio and emission factors ( $\mu \mathrm{g} \mathrm{kg}^{-1}$ input waste)

\begin{tabular}{|c|c|c|c|}
\hline \multicolumn{4}{|l|}{ Usual waste mix } \\
\hline Inputs (2011) & Mass input (t year-1) & $\begin{array}{c}\text { Average PAH } \\
\text { concentration }(\mu \mathrm{g} \\
\left.\mathrm{kg}_{\mathrm{DM}}^{-1}\right)\end{array}$ & PAH input $\left(k\right.$ year $\left.{ }^{-1}\right)$ \\
\hline WWT sludge $(30 \%)^{a}$ & 167,961 & 557 & 22 \\
\hline RDF (70\%) & 391,909 & 7,597 & 2,977 \\
\hline Total PAH input & & & 3,000 \\
\hline Outputs (2011) & $\begin{array}{c}\text { Mass output }\left(\mathrm{m}^{3} \text { year }^{-1}\right. \\
\left.\text { or } t \text { year }{ }^{-1}\right)\end{array}$ & $\begin{array}{c}\text { Average PAH } \\
\text { concentration }\left(\mu \mathrm{g}\left(\mathrm{m}^{3}\right)^{-}\right. \\
\left.1 \text { or } \mu \mathrm{g} \mathrm{kgDM})^{-1}\right) \\
\end{array}$ & PAH output $\left(\mathrm{kg}\right.$ year $\left.{ }^{-1}\right)$ \\
\hline Flue gas & $2,574,275,476$ & 7.46 & 19 \\
\hline Boiler and fly ash & 76,076 & n.d. & n.d. \\
\hline $\begin{array}{l}\text { Flue gas cleaning } \\
\text { residue }\end{array}$ & 15,857 & 36 & 0.57 \\
\hline Bottom ash & 31,966 & 269 & 8.6 \\
\hline Total PAH output & & & 28.4 \\
\hline
\end{tabular}




\begin{tabular}{|l|l|l|l|}
\hline $\begin{array}{l}\text { Total input/output } \\
\text { ratio }^{b}\end{array}$ & $\mathbf{0 . 1 1 \times 1 0 ^ { 3 }}$ & & \\
\hline Emission factors & & & \\
\hline To air & $34 \mathrm{~g} \mathrm{~kg}^{-1}$ input waste & & \\
\hline Total (all outputs) & $51 \mu \mathrm{kg}^{-1}$ input waste & & \\
\hline
\end{tabular}

\begin{tabular}{|c|c|c|c|}
\hline \multicolumn{4}{|c|}{ Co-incineration of ASR } \\
\hline Inputs (2011) & Mass input (t year-1) & $\begin{array}{c}\text { Average PAH } \\
\text { concentration }(\mu \mathrm{g} \\
\left.\mathrm{kg}_{\mathrm{DM}} \mathrm{-}^{-1}\right)\end{array}$ & PAH input $\left(k^{2}\right.$ year $\left.^{-1}\right)$ \\
\hline WWT sludge $(50 \%)^{a}$ & 279,935 & 557 & 37 \\
\hline RDF (25\%) & 139,968 & 7,597 & 1,063 \\
\hline ASR (25\%) & 139,968 & 89,755 & 12,563 \\
\hline Total PAH input & & & 13,664 \\
\hline Outputs (2011) & $\begin{array}{c}\text { Mass output }\left(m^{3} \text { year }^{-1}\right. \\
\left.\text { or } t \text { year }{ }^{-1}\right)\end{array}$ & $\begin{array}{c}\text { Average PAH } \\
\text { concentration }\left(\mu \mathrm{g}\left(\mathrm{m}^{3}\right)^{-}\right. \\
\left.1 \text { or } \mu \mathrm{g} \mathrm{kgDM}{ }^{-1}\right)\end{array}$ & PAH output $\left(\mathrm{kg}\right.$ year $\left.{ }^{-1}\right)$ \\
\hline Flue gas & $2,574,275,476$ & 0.79 & 2.0 \\
\hline Boiler and fly ash & 76,076 & n.d. & n.d. \\
\hline $\begin{array}{l}\text { Flue gas cleaning } \\
\text { residue }\end{array}$ & 15,857 & 12 & 0.19 \\
\hline Bottom ash & 47,629 & 66 & 3.1 \\
\hline Total PAH output & & & 5.3 \\
\hline $\begin{array}{l}\text { Total input/output } \\
\text { ratio }^{b}\end{array}$ & $2.6 \times 10^{3}$ & & \\
\hline \multicolumn{4}{|l|}{ Emission factors } \\
\hline To air & $\begin{array}{l}3.6 \mu \mathrm{g} \mathrm{kg}^{-1} \text { input } \\
\text { waste }\end{array}$ & & \\
\hline Total (all outputs) & $\begin{array}{l}9.5 \mu \mathrm{g} \mathrm{kg}^{-1} \text { input } \\
\text { waste }\end{array}$ & & \\
\hline
\end{tabular}

a Average dry matter content equals $24 \%$

${ }^{\mathrm{b}}$ Whereas for the intermediate data no rounding off was applied, the input-output ratios were rounded off taking into account the accuracy of the analytical data.

Table 1 gives an overview of the PAH concentrations in the waste inputs and in the outputs of the considered FBC. In case of the RDF-sludge mix combustion, the total PAH input is about 100 times higher than the total PAH output, corresponding to a destruction efficiency of $99.05 \% .97 \%$ of the PAH input comes from the RDF, whereas for the outputs the flue gas is the major contributor to the total output $(67 \%)$, followed by the bottom ash (30\%). In case of ASR co-combustion, the total PAH input is about 4.5 times higher than in the RDF-sludge mix and the main PAH source is the ASR $(91 \%)$, as could already be expected from the PAH concentrations in the different waste types given in Section 3.1. The total PAH output is about 5 times lower than in the case of usual waste mix combustion, which indicates that during co-combustion of ASR a better burnout was obtained. The main PAH containing outputs in case of ASR co-combustion are the bottom ash (58\%) and the flue gas (38\%). As a result of the higher PAH input and the lower output, the input/output ratio was 25 
times higher in case of ASR co-combustion compared to RDF-sludge incineration only, corresponding to a PAH destruction efficiency of $99.96 \%$. The PAH destruction efficiency of the FBC is also reflected by the PAH emission factors. In case of the usual waste mix combustion, the total PAH emission factor corresponded to $51 \mathrm{\mu g} \mathrm{kg}^{-1}$ input waste, which is more than 100 times lower than the PAH concentration in the input waste $\operatorname{mix}\left(0.3 \times 557 \mu \mathrm{g} \mathrm{kg}^{-1}+0.7 \times 7,597 \mu \mathrm{g} \mathrm{kg}^{-1}=5,485 \mu \mathrm{g} \mathrm{kg}^{-1}\right)$. In case of ASR co-incineration, the total PAH emission factor corresponded to $9.5 \mu \mathrm{g} \mathrm{kg}^{-1}$ input waste, which is more than 2500 times lower than the PAH concentration in the input waste mix $\left(0.5 \times 557 \mathrm{\mu g} \mathrm{kg}^{-1}+\right.$ $\left.0.25 \times 7,597 \mu \mathrm{g} \mathrm{kg}^{-1}+0.25 \times 89,755 \mu \mathrm{g} \mathrm{kg}^{-1}=24,617 \mu \mathrm{g} \mathrm{kg}^{-1}\right)$. These figures show clearly that in both combustion scenarios, the FBC is a net PAH sink.

\section{Conclusions}

The concentration of the 16 EPA PAHs was determined in samples of different input waste types (WWT sludge, RDF and ASR) and in all the outputs (flue gas, bottom ash, boiler and fly ash and flue gas cleaning residue) of a full scale FBC.

From the analysed waste inputs, RDF and ASR were the main PAH sources, with phenanthrene, fluoranthene and pyrene being the most important PAH. Naphtalene was the most important PAH present in the flue gas sampled at the stack, confirming previous statements that $\mathrm{PAH}$ in combustion gas are newly formed from pyrolytic breakdown products from organic materials in the waste. The boiler and fly ash of the FBC contained no detectable levels of $\mathrm{PAH}$, whereas the flue gas cleaning residue contained low concentrations of naphthalene, probably adsorbed from the flue gas. A comparison of the PAH fingerprint of the combustor outputs and the waste inputs showed that the $\mathrm{PAH}$ present in the bottom ash were mainly remainders from the PAH in the waste inputs and not from recombination of precursors. In the FBC more $\mathrm{PAH}$, present in the input waste, were destroyed than there were formed in the post combustion process. A PAH mass balance was drawn up showing that the total PAH input/output ratio of the FBC ranged from about 100 to about 2,600 depending on the waste input composition and obtained combustion conditions. These figures show that the FBC is clearly a net PAH sink.

Acknowledgements 
The authors wish to thank Guido Wauters, Andres Van Brecht and Pieter Van Royen from Indaver Belgium NV for their kind collaboration.

\section{References}

Agency of Toxic Substances and Disease Registry (ATSDR), 1995. Toxicological Profile for Polycyclic Aromatic Hydrocarbons. ATSDR, Georgia

Atal A., Levendis Y. On the survivability and pyrosynthesis of PAH during combustion of pulverized coal and tire crumb. Combustion and flame 1997, 110, 462-478

Brändli R., Bucheli T., Kupper T., Mayer J., Stadelmann F., Tarradellas J. Fate of PCBs, PAHs and their source characteristic ratios during composting and digestion of source-separated organic waste in full-scale plants. Environmental Pollution 2007, 148, 520-528

Herrera M., Matuschek G., Kettrup A. Thermal degradation of thermoplastic polyurethane elastomers (TPU) based on MDI. Polymer degradation and Stability 2002, 78, 323-331

Johansson I., van Bavel B. Levels of polycyclic aromatic hydrocarbons in incinerator ashes. The science of the total environment 2003, 311, 221-231

Kwon E., Castaldi J. Mechanistic understanding of polycyclic aromatic hydrocarbons (PAHs) from the thermal degradation of tires under various oxygen concentration atmospheres. Environmental Science and Technology 2012, 46,12921-12926

Ruokojärvi P., Ruuskanen J., Ettala M., Rahkonen P., Tarhanen J. Formation of polyaromatic hydrocarbons and polychlorinated organic compounds in municipal waste landfill fires. Chemosphere 1995, 8, 3899-3908

Thomas S., Wornat M. The effect of oxygen on the yields of polycyclic aromatic hydrocarbons formed during the pyrolysis and fuel-rich oxidation of catechol. Fuel 2008, 87, 768-781

Van Caneghem J., Vermeulen I., Block C., Van Brecht A., Van Royen P., Jaspers M., Wauters G., Vandecasteele C. Destruction and formation of PCDD/Fs in a fluidised bed combustor co-incinerating automotive shredder residue with refuse derived fuel and wastewater treatment sludge. Journal of Hazardous Materials 2012, 207-208, 152-158 
Van Caneghem J., Block C., Van Brecht A., Van Royen P., Jaspers M., Wauters G., Vandecasteele

C. Mass balance for POPs in a real scale fluidised bed combustor co-incinerating automotive shredder residue. Journal of Hazardous Materials 2010a,181, 827-835

Van Caneghem J., Block C., Van Brecht A., Wauters G., Vandecasteele C. Mass balance for POPs in hazardous and municipal waste incinerators. Chemosphere 2010b, 78, 701-708

Vehlow J., Bergfeldt B., Hunsinger H. PCDD/Fs and related compounds in solid residues from municipal solid waste incineration-a literature review. Waste Management and Research 2006, 24, $404-418$

VITO. CMA/3/B: Polycyclische aromatische koolwaterstoffen. Compendium voor monsterneming en analyse (2006). https://esites.vito.be/sites/reflabos/2006/Online\%20documenten/CMA 3 B.pdf

VITO. LUC/VI/001: Bepaling van het gehalte aan PAK's. Compendium voor de monsterneming, meting en analyse van lucht (2013). https://esites.vito.be/sites/reflabos/2013/Online\%20documenten/LUC_VI_001.pdf

Watanabe M., Noma Y. Influence of combustion temperature on formation of nitro-PAHs and decomposition and removal behaviours in pilot-scale waste incinerator. Environmental Science and Technology 2009, 43, 2512-2518

Wheatley AD, Sadhra S. Polycyclic aromatic hydrocarbons in solid residues from waste incineration. Chemosphere 2004, 55, 743-74 